\title{
НЕЙРОННА МЕРЕЖА ДЛЯ АНАЛІЗУ ТЕРМОГРАМ ПІД ЧАС ВІДКРИТОЇ ОПЕРАЦІї НА СЕРЦІ
}

Шапошник О.Г., o.shaposhnyk15@gmail.com

Шликов В.В., д.т.н. доцент

v.shlykov@kpi.ua кафедра біомедичної інженерії Національний технічний університет України «Київський політехнічний інститут імені Ігоря Сікорського»

Київ, Україна

Реферат - Запропоновано застосування методів сучасного машинного навчання для аналізу термограм під час відкритої операиій на сериі на основі згорткової нейронної мережі. Аналіз термографічних зображень серия виконується з використанням методики глибокого навчання на основі нейронної мережі, яка забезпечує класифікацію термограм на дві групи - «норма» та «патологія» кровозабезпечення міокарда. Для класифікачії термограм між групами «норми» $i$ «патології» використовується значення градієнта температури - поріг зміни температури на $3{ }^{\circ} \mathrm{C}$ на поверхні міокарда, який дає змогу віднести зображення до однієї з груп. В роботі порівняно різні види нейронних мереж для аналізу термографічних даних, серед яких було обрано оптимальну структуру нейронної мережі, спираючись на значення точності, специфрічності, чутливості та ймовірність помилок першого та другого роду. Досягнуто точності класифікаиї між групами в 65\% для експериментальної вибірки 105 термографічних зображень серия. Підвищення точності класифікаиії потребує подальших рішень шляхом збільшення навчальної вибірки, щуо дасть змогу використання запропонованої архітектури згорткової нейронної мережі у складі термографічної системи скринінгу.

Ключові слова: нейронна мережа, термографія, машинне навчання, аналіз зображень, Pуthоп. 


\section{I. ВСТУП}

Наразі в медицині залишається багато невирішених проблем, зокрема великий пласт задач, які фокусуються на автоматичному аналізі та класифікації різноманітних даних пацієнта для постановки діагнозу. Розробка подібних систем, які базуються на методах математичного моделювання, машинного навчання та штучного інтелекту, є актуальною задачею, яка має попит[1].

Подібні методи здатні забезпечити достовірнішу постановку діагнозу та зменшити наявність хибнопозитивних та хибнонегативних висновків. Це все дозволяє зробити сферу надання медичних послуг більш достовірною, простою та зменшити навантаження на лікарів, через що також буде допускатися менше помилок через перевтому персоналу.

На сьогоднішній день можна спостерігати великий ріст використання термографії [2, 3], як методу діагностики в медичній сфері, зокрема як засіб моніторинг при відкритих операціях на серці.

Не дивлячись на те, що автоматизація в медичній сфері набуває все більшої популярності, але при дослідженні термограм досі залишається популярним візуальний аналіз лікарем, при цьому, підходи до аналізу сильно залежать від органу, який досліджується[4]. Таким чином, лікарі без належного досліду та практики припускаються великої кількості помилок при постановці діагнозу i інколи достовірність діагностики може становити нижче $60 \%$ та менше, що для медичної сфери є доволі низьким показником.

Не дивлячись на те, що сам метод термографії $\epsilon$ доволі точнім та може забезпечувати точність до сотих і абсолютно безпечним, бо застосовується дистанційно та не вимагає ніяких додаткових засобів захисту, але наявність великої кількості хибних розшифрувань термограм призводить до того, що цей метод не отримує швидкого росту в застосуванні. Частіше за все, відбувається гіпердіагностика, через неточний лікарський діагноз, бо температура тіла залежить від великою кількості сторонніх факторів і людське око не завжди може відрізнити переходи в градієнтах температури.

При цьому і для автоматизації аналізу ця сфера залишається досить широкою та складною, бо для кожного окремого органу та зони дослідження необхідно створювати свої унікальні методи аналізу, навіть якщо захворювання має однакову природу та прояви на різних частинах тіла. Особливо методи автоматизації $\epsilon$ актуальними для серцево-судинної сфери, яка займає перше місце по причинам смертності, де для лікування певної кількості захворювань, необхідно проводити операції на відкритому серці.

В медичній сфері все більше популярності набирають методи для автоматизованого аналізу даних. Багато наукових досліджень зазначають перспективність розвитку застосування термограм, які $є$ повністю безпечні під час використання та не мають протипоказань для застосування, в тому числі для діагностичних цілей таких як, виявлення запальних процесів, онкології на початкових етапах, різних захворювань серцево-судинної системи[5-7].

Не дивлячись на те, що термографія використовуються для моніторингу процесу гіпотермії та гіпертермії серця під час штучного кровообігу, цьому неінвазивному методу приділяється недостатня увага, тому популярність використання цього методу росте доволі повільно[8].

\section{II. МЕТА ДОСЛІДЖЕННЯ}

Через те, що під час проведення операції на відкритому серці, серце спочатку необхідно охолодити, а потім зігріти, і цей процес має бути максимально рівномірним, аби не ушкодити міокард, накопичується великий масив візуальної інформації щодо змін температури, який людина не здатна візуально обробити.

До невирішених проблем цієї області підпадає відсутність методу для автоматичного моніторингу стану пацієнта, який базується на сучасних методах машинного навчання, що довели свою результативність в цій області. Зокрема, не виявлення небезпечних ситуацій через різку 
зміну градієнта температури під час операції на відкритому серці, може призвести до відмирання тканин, тому автоматичний моніторинг значно зменшить навантаження на лікаря та прискорить процес обробки даних.

$\begin{array}{clc}\text { Метою } & \text { роботи } \epsilon \text { аналіз } & \text { сучасних } \\ \text { методів } & \text { автоматичної } & \text { обробки }\end{array}$
термографічних зображень серця на основі нейронних мереж згортки та розробка власного класифікатору, який буде виявляти наявність різкої зміни температури (біль ніж $3^{\circ} \mathrm{C}$ ) на поверхні міокарда на основі сучасних методів машинного навчання.

\section{III. АНАЛІЗ ВХІНИХ ДАНИХ}

Як було сказано раніше, перед початком операції серце необхідно охолодити, а після операції-зігріти. Через те, що під час операції необхідно слідкувати за багатьма параметрами пацієнта, а людське око окрім температури серця не здатне швидко та якісно аналізувати безперервний потік інформації, то для моніторингу стану пацієнта доцільно використовувати автоматизовані методи аналізу на основі машинного навчання. Наприклад, доцільно використання методів на основі нейронних мереж, які довели свою ефективність в багатьох сферах по аналізу зображень.

Перед початком проектування системи класифікації теплових зображень, необхідно провести препроцесінг вхідних даних. Через те, що зображення отримувалися на спеціалізованому приладді від компанії FLIR, точність розпізнання температури для якого досягає сотих ${ }^{\circ} \mathrm{C}$, додаткових дій з фільтрацією чи видаленням теплових артефактів на термознімку можна уникнути.

Вхідні дані були отримані в форматі відео формату .mp4, але для навчання нейронної мережі необхідно використовувати формат зображень .jpg, тому спочатку відеопотік було кадровано, а отримані зображення розділено на два класи - «патологія» та «норма», на основі яких буде відбуватися навчання класифікатора.

Також необхідно завчасно виявити зону інтересів. Дані знімки робилися під час операції на відкритому серці, задля того, аби відслідкувати коронарний кровоток, тому основною областю стануть саме коронарні артерії.

Для цього кожне термографічне зображення необхідно відформатувати під однаковий розмір $250 \times 380$, який є не занадто малий аби охопити більшу частини тканини міокарда, та при цьому буде не занадто великий аби класифікатор міг працювати достатньо швидко i не перевантажувати систему. Це дозволяе повноцінно позбавитися від фону, аби він ніяк не впливав на результати класифікації (рис.1).

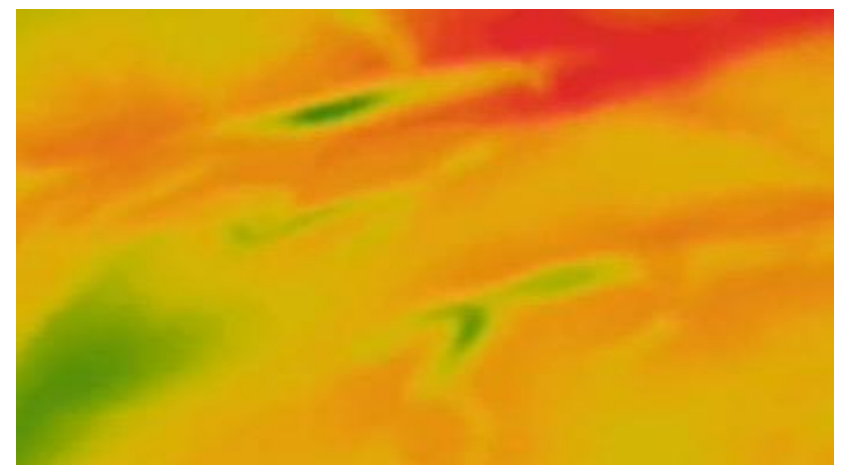

Рис. 1. Сегментоване зображення термограми серця

Таким чином 36 відеопотоків було отримано 105 зображень, які в підсумку було розділено на дві групи «патологія» та «норма». Причому, від 17 зображень серця прийшлося відмовитися, оскільки вони сильно виділялися на фоні інших та могли зіпсувати точність класифікатора.

До першої групи з 64 зображень, відносяться ті термограми, де можна спостерігати градієнт зміни температури вище $3^{\circ} \mathrm{C}$.

До другої групи з 24 елементами було віднесено відповідно ті термознімки, де градієнт температури сягав менше $3^{\circ} \mathrm{C}$. Ліміт в три градуси було обрано через те, що при наявності більшого градієнта температури тканина серця може отримати ураження аж до отримання ушкодження у вигляді рубця.

Також кожна 3 двох груп класифікації була розділена на підгрупи у співвідношенні $70 \%$ до $30 \%$. Більший набір даних буде використано для навчання, інший для валідації. 


\section{IV. СТРУКТУРА НЕЙРОННОЇ МЕРЕЖІ ДЛЯ КЛАСИФІКАЦІї}

РуTorch одна 3 популярних бібліотек, яку використовують для глибокого навчання. Вона $\epsilon$ простою у встановлені та використанні, в іiі основі лежить поняття тензорів, які мають ідентичну основу 3 Numpy. PуTorch дуже добре працює на всіх цих показниках. «Python подібний» стиль кодування спрощує навчання та використання.

Прискорення графічного процесора, підтримка розподілених обчислень та автоматичний розрахунок градієнта допомагає автоматично виконувати зворотнє поширення помилки, починаючи 3 прямого виразу. Звичайно, через Python розрахунки стикаються 3 ризиком уповільнення виконання, але використання високоефективного API C++ (libtorch) нівелює ці витрати. Це робить перехід від дослідницької роботи до виробництва дуже плавним.

Нейронна мережа згортки, яка взята за основу класифікатора складається 3 різних шарів, які можуть чергуватися між собою в довільному порядку. До цих шарів входять: 5 згорткових шарів (convolution layers), агрегувальний шар (subsampling layers) i повнозв'язний шар (fully-connected layer) на виході[9] (рис. 2).

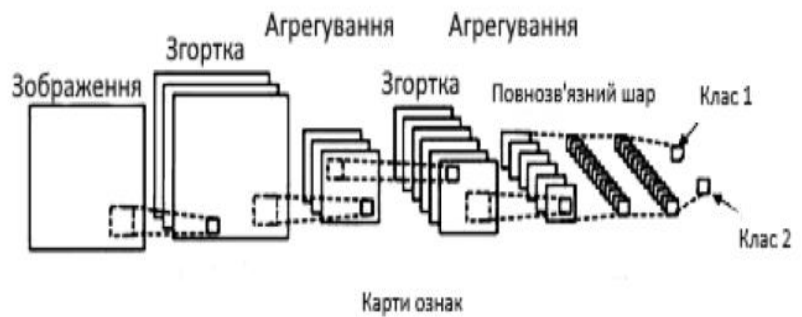

Рис. 2. Архітектура розробленої загорткової нейронної мережі.

У згортковому шарі нейрони, які використовують одні i ті ж ваги, об'єднуються в карти ознак (feature maps), a кожен нейрон карти ознак пов'язаний 3 частиною нейронів попереднього шару. Таким чином, на кожному наступному шарі карта зменшується в розмірі, але збільшується кількість каналів.
При обчисленні мережі виходить, що кожен нейрон виконує згортку деякої області попереднього шару. На практиці це означає здатність розпізнавання складних ієрархій ознак. Зазвичай після проходження декількох шарів карта ознак вироджується в вектор або навіть скаляр, але таких карт ознак стають сотні. На виході шарів згортки мережі додатково встановлюють кілька шарів повно нейронної мережі, на вхід яких подаються кінцеві карти ознак, які використовують роль класифікатора. У ролі класифікатора виступає перцептрон, який складається зі стандартних слоїв, до яких входять елементи трьох видів: S-елементів, А-елементів та одного R-елементу[10].

$\mathrm{S}$-елементи або сенсорний шар може перебувати в двох станах спокою або збудження. Якщо вхідний сигнал перевищує заданий поріг, то елемент вважається збуджений та він передає цей сигнал на наступним шар, з яким він пов'язаний.

А-елемент або асоціативний шар, який пов'язаний 3 декількома S-елементами, та активується тільки тоді, коли сума збуджених $\mathrm{S}$-елементів перевищує певний поріг.

Далі сигнал передається на суматор aбо R-елемент, який на виході може приймати значення +1 чи -1 , в залежності від того, чи сума $є$ суворо додатною чи від'ємною.

Налаштування вагових коефіцієнтів забезпечує навчання персептрона на класифікацію об'єктів. Під час отримання нового елементу збудженні елементи асоціативного шару передають сигнал на наступний R-елемент і відносно того, чи сума є зі знаком плюс чи мінус, елемент відносять до першого чи другого класу.

\section{V. ПОРІВНЯННЯ РЕЗУЛЬТАТІВ ОТРИМАНИХ НА ОСНОВІ ІНЕЙРОННИХ МЕРЕЖ}

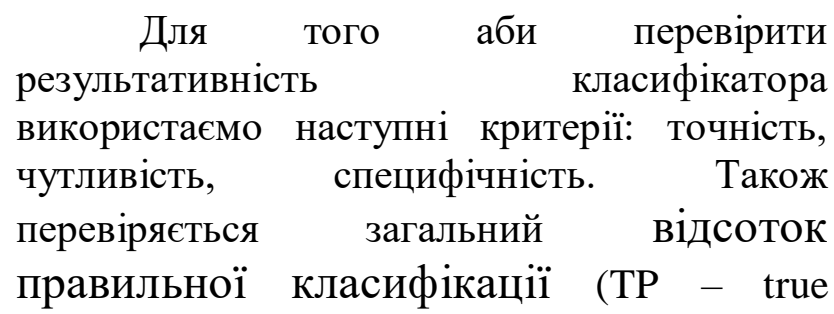


positive, FP - false negative) та наявність помилок першого та другого роду (TN - true negative, FN - false negative). На рисунку 3 представлена робота трьох видів нейронних мереж: дві мережі згортки на 5 та 8 шарів та нейро-нечітка мережа CFNN.

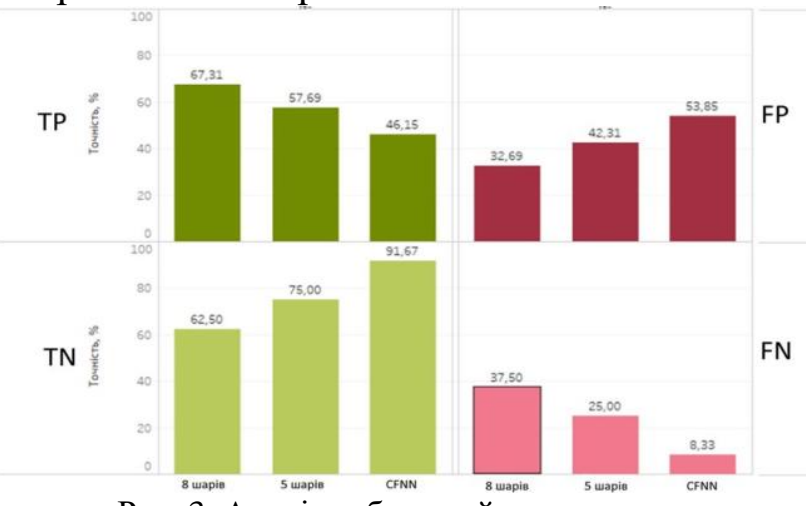

Рис. 3. Аналіз роботи нейронних мереж.

Виходячи з розрахованих значень під час роботи всіх класифікаторів, бачимо, що нейрона мережа на основі 8 шарів дала найкращий результат до розпізнання наявності патологій $(\mathrm{TP}=67,31 \%)$ та майже такий саме результат для виявлення норми $(\mathrm{TN}=62,5 \%)$, при чому дві інші мережі мають протилежний результат, вони гірші для виявлення патології, але гарно розпізнають норму і досягають точності 91\%.

Але при цьому, необхідно звертати увагу на можливість помилок першого та другого роду. В даному випадку розглядання нейронно-нечіткої мережі, яка дає велику точність розпізнавання норми, не є можливим для використання, адже вона допускає багато помилок, коли при наявній патології відносить зображення до класу норму.

Також у більш складної моделі за будовою CFNN під час навчання при збільшені епох відбувається перенавчання моделі та вона починає давати гірші значення на нових даних. Використання таких моделей не $є$ доцільним для класифікації, адже вони занадто сильно прив'язані до вхідних даних і не в змозі настільки ж ефективно класифікувати нові.

Окрім цього, розглянемо також інші статистичні критерії порівняння класифікаторів, аби отримати загальну картину їх роботи, наведених в таблиці 1.
Таблиия 1

Порівняння якості нейронних мереж

\begin{tabular}{|c|c|c|c|}
\hline № & Чутливість & $\begin{array}{c}\text { Специ- } \\
\text { фічність }\end{array}$ & Точність \\
\hline 5 шарів & 57,69 & 75,00 & 63,15 \\
\hline 8 шарів & 67,31 & 62,50 & 65,78 \\
\hline CFNN & 46,15 & 91,67 & 60,52 \\
\hline
\end{tabular}

Не дивлячись на те, всі варіанти архітектури дають дуже близький загальний результат точності, але так як, дана класифікація призначена як допоміжна система для лікаря, під час відкритих операції на серці, особливу увагу необхідно звернути саме точності розпізнання патологій та ймовірності хибно негативних помилок при віднесенні патології до норм. Таким чином, порівняння декількох нейронних мереж показує, що найкращим оптимальним варіантом $є$ використання згорткової мережі 3 8 шарів, яка і забезпечує найбільшу точність в $65,78 \%$.

\section{VI. ВИСНОВКИ ДОСЛІДЖЕННЯ}

В цілому дотягається точність класифікації більш ніж 65\%, що не є повністю задовільним результатом для медичної сфери, тому класифікатор вимагає доопрацювання. В першу чергу, така точність обумовлена тим, що для аналізу було використано мало даних, a при штучному їх збільшенні виникає проблема перенавчання мережі, і вона добре класифікує відомі дані, а на нових видає багато помилок. Оскільки, подібна скринінгова система створювалася як допоміжна система для кардіохірурга, яка забезпечує неінвазивний моніторинг охолодження та зігрівання серця під час штучного кровообігу, тому iї результати можна вважати прийнятними. Для покращення точності запропонованого методу необхідно кожного разу після запуску системи 3 новими даними, давати змогу класифікатору перебудувати свої моделі, оскільки, чим більше різноманітних даних він буде отримувати, тим ставатиме точнішим.

$$
\text { На основі запропонованого }
$$
класифікатора планується створення скринінгової системи, яка дасть змогу реалізувати об'єктивну кількісну оцінку 
результативності операцій шунтування на відкритому серці. Якщо за результатами класифікації зображень нейронною мережею під час охолодження та зігрівання серця побудувати гістограми ймовірності, ці дані шляхом їх порівняння нададуть можливість оцінити функціональний стану кровопостачання міокарда. Наприклад, через те, що наприкінці хірургічної операції проводиться відновлення нормального кровотоку, після відновлення серцевих скорочень різкої зміни градієнта температур на поверхні міокарда не має спостерігатися.

\section{ПЕРЕЛІК ПОСИЛАНЬ}

1. Ravı, D., Wong, C., Deligianni, F. Deep Learning for Health Informatics. IEEE Journal of Biomedical and Health Informatics. 2017. Vol. 521. C. 436-444.

2. Bichinho, G. L., Gariba, M. A., Sanches, I. J. A computer tool for the fusion and visualization of thermal and magnetic resonance images. Journal of Digital Imaging. 2009. Vol. 22, No. 5. C. $527-534$.

3. Zayaats, G. A., Koval, V. T. Medical thermal imaging - a modern method of functional diagnostics. Health. Medical ecologe. Science. 2010. Vol. 43, No. 3. C. 27-33.

4. Weiner, B. G. Matrix thermal imaging in physiology: the study of vascular reactions, perspiration and thermoregulation in humans: Novosibirsk: Publishing House of the Siberian Branch of the Russian Academy of Sciences, 2004. 96c.

5. Blumin, R. B., Naumova, E. M., Khadartsev, A. A. Technologies of contactless diagnostics. Bulletin of new medical technologies. 2008. Vol. 15, No. 4. C. 146-149.

6. Kozhevnikova, I. S., Pankov, M. N., Gribanov, A. V., та ін. Application of infrared thermograoohy in modern medicine. Human ecology. 2017. C. 39-46.

7. Etehadtavakol, M., Ng, E. Y. K. Thermography as a Potential Non-Contact Method in the Early Detection of Cancer. Journal Mech. Med. Bio. 2013. Vol. 2.

8. Nowakowski, A., Kaczmarek, M., Wtorek, J., та ін. Thermographic and electrical measurements for cardiac surgery inspection: Proceedings of the 23rd Annual EMBS International Conference, 01. C. 2874-2877.

9. Schmidhuber, J. Deep Learning in Neural Networks: an Overview. . Neural Networks. 2015. Vol. 1. C. 85-117.

10. LeCun, Y., Bottou, L., Bengio, Y., та ін. Gradient-based learning applied to document recognition. Proceedings of IEEE. 1998. Vol. 86, No. 11. C. 2278-2324. 
УДК 616.1-616.7

\title{
НЕЙРОННАЯ СЕТЬ ДЛЯ АНАЛИЗА ТЕРМОГРАММ ВО ВРЕМЯ ОПЕРАЦИЙ НА ОТКТІТОМ СЕРДЦЕ
}

\author{
Шапошник О.Г., \\ магистр \\ o.shaposhnyk15@gmail.com \\ Шлыков В.В., \\ д.Т.н., доцент \\ v.shlykov@kpi.ua \\ кафедра биомедицинской инженерии \\ Национальный технический университет Украины \\ «Киевский политехнический институт имени Игоря Сикорского» \\ Киев, Украина
}

Реферат - Предложено применение методов современного машинного обучения для анализа термограмм при открытой операций на сердие на основе сверточной нейронной сети. Анализ термографических изображений сердиа выполняется с использованием методики глубокого обучения на основе нейронной сети, которая обеспечивает классификачию термограмм на две группы - «норма» и «патология» кровоснабжения миокарда. Для классификачии термограмм между группами «нормы» и «патологии» используется значение градиента температуры - порог изменения температуры на $3{ }^{\circ} \mathrm{C}$ на поверхности миокарда, который позволяет отнести изображение к одной из групп. В работе сравниваются различные виды нейронных сетей для анализа термографических данных, среди которых была избрана оптимальная структура нейронной сети, опираясь на значение точности, специфичности, чувствительности и вероятность ошибок первого и второго рода. Достигнута точность классификащии между группами в $65 \%$ для экспериментальной выборки 105 термографических изображений сердия. Повышение точности классификации требует дальнейших решений путем увеличения обучающей выборки, что позволит использование предложенной архитектуры сверточной нейронной сети в составе термографической системы скрининга.

Ключевые слова: нейронная сеть, термография, машинное обучение, анализ изображений, Python. 


\title{
NEURAL NETWORK FOR ANALYSIS OF THERMOGRAMS DURING OPERATIONS ON THE HEART OPENED
}

\author{
O.Shaposhnyk, \\ Master student \\ o.shaposhnyk15@gmail.com \\ V.Shlikov, \\ Ph.D., Associate Professor \\ v.shlykov@kpi.ua \\ Department \\ of Biomedical Engineering \\ National Technical University of Ukraine \\ "Igor Sikorsky Kyiv Polytechnic Institute" \\ Kiev, Ukraine
}

\begin{abstract}
The application of modern machine learning methods for the analysis of thermograms during open heart surgery on the basis of a convolutional neural network is proposed. The analysis of thermographic images of the heart is performed using the technique of deep learning based on the neural network, which provides the classification of thermograms into two groups - "norm" and "pathology" of the myocardial blood supply. To classify thermograms between the groups "normal" and "pathology", the value of the temperature gradient is used - the threshold of temperature change by $3^{\circ} \mathrm{C}$ on the surface of the myocardium, which allows to assign the image to one of the groups. The paper compares different types of neural networks for the analysis of thermographic data, among which the optimal structure of the neural network was chosen based on the values of accuracy, specificity, sensitivity and probability of errors of the first and second kind. A classification accuracy between groups of 65\% was achieved for an experimental sample of 105 thermographic images of the heart. Improving the accuracy of classification requires further solutions by increasing the training sample, which will allow the use of the proposed architecture of the convolutional neural network as part of the thermographic screening system.
\end{abstract}

Keywords: neural network, thermography, machine learning, image analysis, Python. 